\title{
Üst Gastrointestinal Sistemde Yabancı Cisimlerin Değerlendirilmesi: Tanı ve Tedavi
}

\author{
(iD) Hasan Çantay ${ }^{1}$, (DD) Turgut Anuk ${ }^{2}$, (iD) Barlas Sülü ${ }^{3}$, (iD) Kenan Binnetoğlu ${ }^{1}$, (D) Tülay Diken Allahverdi², \\ (iD) Doğan Gönüllü ${ }^{3}$ \\ ${ }^{1}$ Dr. Öğr. Üyesi. Kafkas Üniversitesi Tıp Fakültesi, Genel Cerrahi Anabilim Dalı, Kars, Türkiye. \\ ${ }^{2}$ Doç. Dr. Kafkas Üniversitesi Tıp Fakültesi, Genel Cerrahi Anabilim Dalı, Kars, Türkiye. \\ ${ }^{3}$ Prof. Dr. Kafkas Üniversitesi Tıp Fakültesi, Genel Cerrahi Anabilim Dalı, Kars, Türkiye.
}

Öz

\section{Üst Gastrointestinal Sistemde Yabancı Cisimlerin Değerlendirilmesi: Tanı ve Tedavi}

Amaç: Araștırmada, yabancı cisim yutulması nedeniyle genel cerrahi kliniğinde acil endoskopi ișlemi uygulanan ve endoskopi ișleminin yetersiz kaldığı durumlarda cerrahi yöntem ile tedavi edilen vakaların değerlendirilmesi amaçlanmıştır.

Gereç ve Yöntem: Tanımlayıcı nitelikte yapılan araștırmanın verileri yabancı cisim yutan hastaların dosyalarından elde edilmiştir. 20172020 yılları arasında 21 yabancı cisim yutma vaka dosyaları taranmıștır. Araștırmanın verileri SPSS paket programında analiz edildi. Analizlerde frekanslar, yüzde ve ortalama, ortanca kullanıldı.

Bulgular: Yabancı cisim yutanların yarıdan fazlası (\%52.3) erkektir. Yabancı cisimlerin \%57.1 organik olup, en fazla en fazla üst özofagusta yerleșmiștir (\%47.6). En sık görülen semptom disfaji (\%38.1), \%57.1’i ayaktan tedavi edilerek yatıșa gerek duyulmamıştır. Komplikasyon oranı \%14.3'tür. Vakaların \%90.5’i endoskopi ile tanı konularak tedavi edilmiştir.

Sonuç: Yabancı cisimlerin gerek tanı ve gerekse tedavisinde en önemli yöntem endoskopik ișlemdir. Endoskopinin yetersiz olduğu sınırlı sayıda vakada ise cerrahi gerekmektedir.

Anahtar Kelimeler: Yabancı Cisim, Endoskopi, Gastrointestinal, Özofagus

\section{Abstract}

Evaluation of Foreign Bodies in the upper Gastrointestinal System: Diagnosis and Treatment

Objective: The aim of this study was to evaluate the cases treated surgically in cases where emergency endoscopy was performed in the general surgery clinic due to foreign body ingestion and the endoscopy procedure was insufficient.

Methods: The data of the descriptive study were obtained from the files of patients who ingested foreign bodies. Between 2017-2020, 21 foreign body ingestion case files were scanned. The data of the research were analyzed in the SPSS package program. Frequencies, percentage and mean, median were used in the analyzes.

Results: More than half (52.3\%) of those who ingested foreign bodies were men. 57.1\% of foreign bodies are organic and mostly localized in the upper esophagus (47.6\%). The most common symptom is dysphagia (38.1\%), 57.1\% was treated on an outpatient basis and hospitalization was not required. Complication rate is $14.3 \% .90 .5 \%$ of the cases were diagnosed and treated by endoscopy. Conclusion:The most important method in both diagnosis and treatment of foreign bodies is endoscopic procedure. Surgery is required in a limited number of cases where endoscopy is insufficient.

Keywords: Foreign Body, Endoscopy, Gastrointestinal, Esophagus

Nasıl Atıf Yapmalı: Çantay H, Anuk T, Binnetoğlu K, Allahverdi TD, Gönüllü D. Üst Gastrointestinal Sistemde Yabancı Cisimlerin Değerlendirilmesi: Tanı ve Tedavi. MKÜ Tıp Dergisi. 2021;12(44):186-190. https://doi.org/10.17944/mkutfd.935615 


\section{Gíriș}

Yabancı cisim yutulması, özefagus perforasyonu ve mediastinit gibi morbidite ve mortalite açısından önemli riskleri içermektedir. Dolayısıyla komplikasyon gelișimini engellemek için acil tıbbi müdahale gerekmektedir. Özellikle; gıdaIarın hızlı şekilde alınması, obezite, diş protezi kullanan yaşlı kişiler, psikiyatrik ve nörolojik defisiti olan bireyler yabancı cisim yutulması açısından risk gruplarını olușturmaktadır (1-3).

Yabancı cismin büyüklüğü, yerleșim yeri, șekli, kimyasal bileșeni; cismin yutulmasından tedaviye kadar geçen süre gerek tanı ve gerekse tedavide güçlüklere neden olabileceği gibi komplikasyon sıklığını da arttırabilmektedir. Yabancı cisimler çoğunlukla radyoopak olduklarından dolayı, tanıda sıklıkla direkt radyografi yeterlidir. Ancak bazı durumlarda mide duodenum grafisi ve bilgisayarlı tomografi de tanı koymada yardımcı seçenekler arasındadır $(4,5)$.

Özofagusta takılan cisimlerin çıkarılmasında anestezi eșliğinde rijit özofagoskopi güvenli ve kolay bir ișlemdir. YabanCı cisim, mide ve ince bağırsaklara geçmiş ise büyük oranda kendiliğinden gastrointestinal sistemden atılabilmektedir. Ancak, bazı durumlarda bu atılım gerçekleșememekte ve endoskopik olarak yabancı cisimlerin çıkartılabileceği gibi, bazı durumlarda da cerrahi müdahale gerektirebilmektedir. Sonuç olarak gastroskopi, üst gastrointestinal sistemdeki yabanCı cisimlerin tanı ve tedavisinde önem arz etmektedir (6-9).

Araștırmada, yabancı cisim yutulması nedeniyle genel cerrahi kliniğinde acil endoskopi ișlemi uygulanan ve endoskopi ișleminin yetersiz kaldığı durumlarda cerrahi yöntem ile tedavi edilen vakaların değerlendirilmesi amaçlanmıștır.

\section{GEREC VE YÖNTEM}

Tanımlayıcı nitelikte yapılan araștırmanın verileri; 2017 2020 yılları arasında Kafkas Üniversitesi Tıp Fakültesi Hastanesi acil cerrahi polikliniğine yabancı cisim yutma hikâyesi ile bașvuran ve yapılan tetkikler sonrasında üst gastrointestinal sistemde yabancı cisim saptanan, endoskopik ve cerrahi olarak tedavi edilen hastaların dosyalarından elde edilmiștir. Tanı konulan ve müdahale edilen hasta sayısı toplam 21'dir. Hastaların dosyalarının incelenmesi sonucunda kișiye ait yaş, cinsiyet, hastaların semptomları, yabancı cismin niteliği, yabancı cismin yerleșim yeri, tedavi prosedürleri, yatıș süresi, komplikasyon ve komplikasyonlara karșı tedavi șekline ilișkin bilgiler kaydedilmiștir.

\section{İstatistiksel Analiz}

İstatistiksel analizler için SPSS version 20 for Windows yazııım paketi kullanıldı. Analizlerde frekanslar, yüzde ve ortalama, ortanca kullanıldı.

\section{BULGULAR}

Yabancı cisim yutanların \%52.3'ünü erkekler \%47.7'sini ise kadınlar olușturmuștur. Yaș grupları açısından değerlendirildiğinde ise yabancı cisim yutanların \%33.3 30 yaștan küçük iken, \%47.7'si 30-64 yaș arası ve yaklașık olarak her 5 vakadan birisini ise yașlılar olușturmuștur (Tablo 1). Vakaların yaș ortalaması 43.6 ( \pm 18.6$)$, ortancası 41 olup minimum değer 18 iken, maksimum yaș 73'dür.

\section{Tablo 1.Yabanct cisim nitelı̆̆i, semptom, yerleşim yeri, tedavi ve komplikasyonların yaş ve einsiyet ïzerine dağılımı}

\begin{tabular}{|c|c|c|c|c|c|c|c|c|c|c|c|c|}
\hline \multirow{3}{*}{ Cisim, semptom, yerleșim yeri, tedavi, komplikasyon } & \multicolumn{6}{|c|}{ Yass } & \multicolumn{4}{|c|}{ Cinsiyet } & & \\
\hline & \multicolumn{2}{|c|}{$<30$ yass } & \multicolumn{2}{|c|}{$30-64$ yas } & \multicolumn{2}{|c|}{$\geq 65$ yas } & \multicolumn{2}{|c|}{ Erkek } & \multicolumn{2}{|c|}{ Kadın } & \multicolumn{2}{|c|}{ Toplam } \\
\hline & $\mathrm{n}$ & $\%$ & $\mathrm{n}$ & $\%$ & $\mathrm{n}$ & $\%$ & $\mathrm{n}$ & $\%$ & $n$ & $\%$ & $\mathrm{n}$ & $\%$ \\
\hline $\begin{array}{l}\text { Cismin niteliği } \\
\text { Organik } \\
\text { İnorganik }\end{array}$ & $\begin{array}{l}1 \\
6\end{array}$ & $\begin{array}{c}8.3 \\
66.7\end{array}$ & $\begin{array}{l}8 \\
2\end{array}$ & $\begin{array}{l}66.7 \\
22.2\end{array}$ & $\begin{array}{l}3 \\
1\end{array}$ & $\begin{array}{l}25.0 \\
11.1\end{array}$ & $\begin{array}{l}7 \\
4\end{array}$ & $\begin{array}{l}58.3 \\
44.4\end{array}$ & $\begin{array}{l}5 \\
5\end{array}$ & $\begin{array}{l}41.7 \\
55.6\end{array}$ & $\begin{array}{l}12 \\
9\end{array}$ & $\begin{array}{l}57.1 \\
42.9\end{array}$ \\
\hline $\begin{array}{l}\text { Semptom } \\
\text { Yok } \\
\text { Var }\end{array}$ & $\begin{array}{l}6 \\
1\end{array}$ & $\begin{array}{c}75.0 \\
7.7\end{array}$ & $\begin{array}{l}1 \\
9\end{array}$ & $\begin{array}{l}12.5 \\
69.2\end{array}$ & $\begin{array}{l}1 \\
3\end{array}$ & $\begin{array}{l}12.5 \\
23.1\end{array}$ & $\begin{array}{l}3 \\
8\end{array}$ & $\begin{array}{l}37.5 \\
61.5\end{array}$ & $\begin{array}{l}5 \\
5\end{array}$ & $\begin{array}{l}62.5 \\
38.5\end{array}$ & $\begin{array}{c}8 \\
13\end{array}$ & $\begin{array}{l}38.1 \\
61.9\end{array}$ \\
\hline $\begin{array}{l}\text { Yerlessim yeri } \\
\text { Üst özfagus } \\
\text { Orta özfagus } \\
\text { Mide }\end{array}$ & $\begin{array}{l}- \\
1 \\
6\end{array}$ & $\begin{array}{c}- \\
33.3 \\
75.0\end{array}$ & $\begin{array}{l}3 \\
- \\
1\end{array}$ & $\begin{array}{l}70.0 \\
66.7 \\
12.5\end{array}$ & $\begin{array}{l}3 \\
- \\
1\end{array}$ & $\begin{array}{c}30.0 \\
- \\
12.5\end{array}$ & $\begin{array}{l}6 \\
2 \\
3\end{array}$ & $\begin{array}{l}60.0 \\
66.7 \\
37.5\end{array}$ & $\begin{array}{l}4 \\
1 \\
5\end{array}$ & $\begin{array}{l}40.0 \\
33.3 \\
62.5\end{array}$ & $\begin{array}{l}10 \\
3 \\
8\end{array}$ & $\begin{array}{l}47.6 \\
14.3 \\
38.1\end{array}$ \\
\hline $\begin{array}{l}\text { Tedavi } \\
\text { Endoskopik çkarma } \\
\text { Endoskopik itme } \\
\text { Cerrahi ișlem }\end{array}$ & $\begin{array}{l}5 \\
1 \\
1\end{array}$ & $\begin{array}{l}35.7 \\
20.0 \\
50.0\end{array}$ & $\begin{array}{l}3 \\
1 \\
-\end{array}$ & $\begin{array}{l}42.9 \\
60.0 \\
50.0\end{array}$ & $\begin{array}{l}3 \\
1 \\
-\end{array}$ & $\begin{array}{c}21.4 \\
20.0 \\
-\end{array}$ & $\begin{array}{l}6 \\
4 \\
1\end{array}$ & $\begin{array}{l}42.8 \\
80.0 \\
50.0\end{array}$ & $\begin{array}{l}8 \\
1 \\
1\end{array}$ & $\begin{array}{l}57.2 \\
20.0 \\
50.0\end{array}$ & $\begin{array}{l}14 \\
5 \\
2\end{array}$ & $\begin{array}{c}66.7 \\
23.8 \\
9.5 \\
\end{array}$ \\
\hline $\begin{array}{l}\text { Yatıs süresi } \\
\text { Yatıs yapılmayan } \\
\text { En az bir gün yatan }\end{array}$ & $\begin{array}{l}4 \\
3\end{array}$ & $\begin{array}{l}33.3 \\
33.3\end{array}$ & $\begin{array}{l}1 \\
3\end{array}$ & $\begin{array}{l}58.4 \\
33.3\end{array}$ & $\begin{array}{l}1 \\
3\end{array}$ & $\begin{array}{c}8.3 \\
33.4\end{array}$ & $\begin{array}{l}6 \\
5\end{array}$ & $\begin{array}{l}50.0 \\
55.6\end{array}$ & $\begin{array}{l}6 \\
4\end{array}$ & $\begin{array}{l}50.0 \\
44.4\end{array}$ & $\begin{array}{c}12 \\
9\end{array}$ & $\begin{array}{l}57.1 \\
42.9\end{array}$ \\
\hline $\begin{array}{l}\text { Komplikasyon } \\
\text { Yok } \\
\text { Var }\end{array}$ & $\begin{array}{l}7 \\
-\end{array}$ & $\begin{array}{c}38.9 \\
-\end{array}$ & $\begin{array}{l}3 \\
1\end{array}$ & $\begin{array}{l}44.4 \\
66.7\end{array}$ & $\begin{array}{l}3 \\
1\end{array}$ & $\begin{array}{l}16.7 \\
33.3\end{array}$ & $\begin{array}{l}9 \\
2\end{array}$ & $\begin{array}{l}50.0 \\
66.7\end{array}$ & $\begin{array}{l}9 \\
1\end{array}$ & $\begin{array}{l}50.0 \\
33.3\end{array}$ & $\begin{array}{c}18 \\
3\end{array}$ & $\begin{array}{l}85.7 \\
14.3\end{array}$ \\
\hline Toplam & 7 & 33.3 & 4 & 47.7 & 4 & 19.0 & 11 & 52.3 & 10 & 47.7 & 21 & 100.0 \\
\hline
\end{tabular}

*satır yüzdesi, **sütun yüzdesi 
Araștırmada yabancı cisimlerin \%57.1'i organik olup, \%42.9'u inorganik niteliktedir (Tablo 1). Buna göre toplam yabancı cisimlerin \%19.0'unu kemik parçası, \%14.3'ünü kemikli et, \%14.3'ünü et parçası \%9.5’ini balık kılçı̆̆ı; \%32.8’ini iğne (toplu iğne, dikiș iğnesi) ve \%9.5’ini ise raptiye olușturmaktadır (Tablo 2).

Tablo 2.Yabanes cisimlerin niteliği, semptomlar ve

komplikasyonlar

\begin{tabular}{|l|c|c|l|c|c|}
\hline Yabancı cisimlerin niteliği & $\mathbf{n}$ & $\%$ & Semptomları & $\mathbf{n}$ & $\%$ \\
\hline I-Organik yabancı cisimler & & & Semptom yok & 8 & 38.1 \\
\hline Balık kııçı̆ı̆ & 2 & 9.5 & Disfaji & 8 & 38.1 \\
\hline Et parçası & 3 & 14.3 & 0dinofaji & 3 & 14.3 \\
\hline Kemikli et & 3 & 14.3 & Hipersalivasyon & 2 & 9.5 \\
\hline Kemik parçası & 4 & 19.0 & Komplikasyonlar & & \\
\hline II-İnorganik yabancı cisimler & & & Y0k & 18 & 85.7 \\
\hline Iğne & 5 & 23.8 & Mukozal yaralanma & 2 & 9.5 \\
\hline Raptiye & 2 & 9.5 & Apse & 1 & 4.8 \\
\hline Cam parçası & 1 & 4.8 & & & \\
\hline Diş protezi & 1 & 4.8 & & & \\
\hline
\end{tabular}

Hastaların en fazla görülen semptomları disfaji (\%38.1), odinofaji (\%14.3), hipersalivasyon (\%9.5) iken \%38.1'inde yabancı cisim yutma hikayesi olmasına rağmen, herhangi bir semptom saptanmamıștır (Tablo 1 ve Tablo 2).

Yabancı cisimler en fazla üst özofagusa yerleșmiş iken (\%47.6) ikinci sıklıkta mideye (\%38.1) ve en az ise orta özofagusu (\%14.3) yerleșmiștir (Tablo 1).

Tedavide yabancı cisimlerin \%66.7'si endoskopik olarak çıkarılmıștır. Kalan vakaların \%23,8'ine endoskopik mideye itme ve \%9.5'ine ise cerrahi ișlem uygulanmıștır (Tablo 1).

Tablo 1 takip edildiğinde vakaların çoğunluğu (\%57.1) ayaktan tedavi edilmiş iken, \%42.9'u en az bir gün olacak şekilde genel cerrahi servisinde yatırılarak tedavi edilmiștir (Tablo 1).

Araştırma komplikasyonlar açısından değerlendirildiğinde ise vakaların \%85.7'sinde herhangi bir komplikasyon gelișmemiş iken, \%14.3'ünde (mukozal yaralanma, yara yeri enfeksiyonu-apse) komplikasyon varlığı belirlenmiștir (Tablo 1).

\section{TARTIȘMA}

Apendiks dıșında gastrointestinal sistemin dar yerlerden biri olan özofagus, bu anatomik darlık nedeniyle yabancı cisimlerin en sık takıldığı organdır. Bunun yanında ikinci sırada da midede tespit edilmektedir. Araștırmada üst gastrointestinal sistemde yabancı cisimler; en sık üst özofagusta, ikinci sırada midede ve üçüncü sırada da orta özofagusta saptanmıștır $(1,10)$.
Araștırmamızda yabancı cisim yutanlar yaş ve cinsiyet açısından değerlendirildiğinde; vakaların büyük kısmını erkekler olușturmuștur ve vakaların yaș ortalaması ise 43.6 ( \pm 18.6$)$ olarak bulunmuștur. Yapılan çalıșmalarda, benzer olarak erkek vakaların kadın vakalardan daha fazla olduğu ve yaș ortalamasının ise benzer şekilde 44-45 yaş civarıdır olduğu belirtilmiștir $(1,11,12)$.

Araștırmada yabancı cisimlerin çoğu organik olup, bunlar da sıklık sırasına göre kemik parçası, kemikli et, et parçası ve balık kılçı̆̆ı şeklindedir. İnorganik olanlar ise, iğne (toplu iğne, dikiş iğnesi) ve raptiyedir. Yapılan benzer çalışmaların büyük bir kısmında organik, daha az kısmında ise inorganik cisimler daha fazla tespit edilmiștir (13-17). Bu araștırmada organik cisimlerin daha fazla olmasının muhtemel nedeninin; hastalarda hızlı yeme alıșkanlığının olması, et ve et ürünlerinin daha dens özellikte olması, bölgede hayvancılığın yaygın olması ve buna bağlı olarak et tüketimimin fazla olmasından kaynaklanabileceği düșünülmektedir.

Çalıșmadaki hastalarda görülen semptomlar sırasıyla; en sık disfaji ve yabancı cisim yutmasına rağmen herhangi bir semptomu olmayanlar iken, ikinci sırada odinofaji ve üçüncü sırada hipersalivasyon șeklindedir. Bu konuda yapılan çalıșmalarda da semptomların benzer olduğu görülmüștür. Ayrıca araștırmada olduğu gibi yabancı cisim yutma hikayesi olmasına rağmen, herhangi bir semptom saptanmayan vakalar da mevcuttur (1, 18-21).

Araștırmada endoskopi temel tanı ve tedavi yöntemi olarak uygulanmıștır. İncelenen çalıșmalara bakılacak olursa, yabancı cisimlerin çoğu radyoopak olduğundan direkt grafi ile tanı koymak mümkün iken; nonopak yabancı cisimler direkt grafide görülmeyebileceğinden, mide duodenum grafisi ve bilgisayarlı tomografi de tanıda yardımcı yöntemlerdir. Gastroskopi ise, hem tanı hem de tedavi yöntemi olarak öne çıkmaktadır $(22,23)$.

Araștırmada yabancı cisimlerin \%66.7'si endoskopik olarak çıkarılmıștır. \%23.8'i endoskopik mideye itme șeklinde tedavi edilmişken, \%9.5'ine cerrahi tedavi uygulanmıștır. Literatürde de çalıșmaların büyük kısmında, benzer șekilde üst gastrointestinal sistemdeki yabancı cisimlerin tedavisinde gözlem ve endoskopi temel tedavi şeklidir. Ancak endoskopi ile tedavi edilemeyen vakalarda cerrahi tedavilerin uygulandığı da bildirilmektedir $(22,23)$.

Çalışmada alkol bağımlısı ve psikiyatrik bozukluğu olan bir vakada, midede cam parçaları saptanmıștır ve endoskopik olarak çıkarılmıştır. Epilepsi hastalığı olanlarda, alkol bağımlılarında ve zeka geriliği olanlarda da yabancı cisimlere sıklıkla rastlanmaktadır (24).

Araștırmada endoskopik olarak tedaviye yanıt alınamayan, dikiş iğnesi ve iğne yutan iki hastada yabancı cisim cer- 
rahi tedavi ile çıkarılmıștır. Medikal tedavi- konservatif takip ve endoskopik ișlemlerden yanıt alınamayan semptomatik hastalarda tek tedavi seçeneği cerrahi müdahaledir (25).

Yabancı cisimler, bulunduğu bölgede bası, inflamasyon ve ülserasyon yaparak komplikasyonlara ve bu kompikasyonlar sonucu ciddi kanama, perforasyon ve mortaliteye sebep olabilmektedirler. Çalıșmada tedavi sonrasında üç hastada komplikasyon gelișmiş olup, iki hastada yabancı cisme bağlı mukozal laserasyon ve cerrahi tedavi edilen bir hastada cerrahi alan yerinde enfeksiyon ve abse gelișimi görüldü (26).

Bu çalıșmadaki vakaların çoğunluğu endoskopik olarak tedavi edilerek ayaktan tedavi edilmiş iken, bir kısmı da en az bir gün olacak șekilde genel cerrahi servisinde yatırılarak tedavi edilmiştir. Endoskopik tedavi ișlemi, gözlem veya cerrahi tedaviye kıyasla hastanede yatış süresini kısaltmaktadır (27).

\section{SONUC}

Sonuç olarak araștırmada yabancı cisimler en sık üst özofagusa takılmış olup, erkeklerde, 40 yaș civarında daha fazla görülmektedir. Ayrıca en sık saptanan semptom disfaji olup, yabancı cisimlerin büyük kısmı organik kökenli olup, tanı ve tedavide en etkin yöntem endoskopidir. Endoskopik girişimlerle majör cerrahi girişim ihtiyacı azalmakta, hastanede yatış süresi, olası cerrahinin getirdiği morbidite ve mortalitede azalma sağlanabilmektedir.

\section{BILDIRIMLER}

Değerlendirme

Dıș danıșmanlarca değerlendirilmiștir.

Çıkar Çatıșması

Yazarlar bu makale ile ilgili herhangi bir çıkar çatışması

bildirmemișlerdir.

Finansal Destek

Yazarlar bu çalıșma sırasında herhangi bir finansal destek kullanmamışlardır.

Etik Beyan

Bu çalıșma için Kafkas Üniversitesi Tıp Fakültesi Girișimsel Olmayan Klinik Araștırmalar Etik Kurulundan 30.09.2020 tarih ve 238 sayılı yazı ile izin alınmış olup, Helsinki Bildirgesi kriterleri göz önünde bulundurulmuștur.

\section{KAYNAKLAR}

1. Yenidoğan E, Okan I, Kayaoğlu H, Özsoy Z, Tali S, Şahin M. Özofagusa Takılan Yiyeceklerin Endoskopik Olarak Çıkarılması. Gaziosmanpaşa Üniversitesi Tıp Fakültesi Dergisi 2014;6 (2):119-128.

2. Weissberg D, Refaely Y. Foreign bodies in the esophagus. Ann Thorac Surg. 2007;84(6):1854-7. https://doi.org/10.1016/j. athoracsur.2007.07.020.

3. Kay M, Wyllie R. Pediatric foreign bodies and their management. Curr Gastroenterol Rep. 2005;7(3):212-8. https://doi.org/10.1007/s11894-005-0037-6.
4. Thomas W. Sadler Langman's Medical Embryology Lippincott Williams \& Wilkins. 2006;10: 112.

5. Smith MT, Wong RK. Esophageal foreign bodies: types and techniques for removal. Curr Treat Options Gastroenterol 2006;9:75-84.

6. Athanassiadi K, Gerazounis M, Metaxas E, Kalantzi N. Management of esophageal foreign bodies: a retrospective review of 400 cases. Eur J Cardiothorac Surg. 2002;21(4):6536. https://doi.org/10.1016/S1010-7940(02)00032-5.

7. Khurshid Z, Abdelbasit Elsayed Ali AE, Al Hamidi SAA. et al. Foreign Body Ingestion in Children: A Hospital Based Experience in Riyadh. Acta Scientific Paediatrics :2:10 (2019): 13-19.

8. Chaudhari SKS, Chaudhary SM. Endoscopic management of foreign bodies in the upper gastrointestinal tract. isj. 2020;7;7:2226-30. https:// doi.org/10.18203/2349-2902.

9. Ruan WS, Li YN, Feng MX, Lu YQ. Retrospective observational analysis of esophageal foreign bodies: a novel characterization based on shape. Scientific Reports. 2020; 10: 4273. https:// doi.org/10.1038/s41598-020-61207-8.

10. Yalçınkaya I, Er M. Trakeobronş ve özofagus yabancı cisimlerinin tanı, tedavi ve komplikasyonları. Van Tıp Dergisi 1998;5:31-4.

11. Kefeli A, Başyiğit S, Yeniova A, Nazlıgül Y, Küçükazman M, Aktaş B. Üst gastrointestinal sistem yabancı cisimleri. Dicle Tıp Dergisi 2014;41(1):195-198. https://doi.org/10.5798/ diclemedj.0921.2014.01.0398.

12. Çobanoğlu U, Yalçınkaya İ. Özofagus yabancı cisimleri: 175 olgunun analizi. Turkish J Thorac Cardiovasc Surg 2008; 16(4): 244-249.

13. Al-Qudah A, Daradkeh S, Abu-Khalaf M. Esophageal foreign bodies. Eur J Cardiothorac Surg. 1998;13(5):494-8. https://doi. org/10.1016/s1010-7940(98)00068-2.

14. Soprano JV, Mandl KD. Four strategies for the management of esophageal coins in children. Pediatrics. 2000;105(1):5. https://doi.org/10.1542/peds.105.1.e5.

15. Celik S, Aydemir B, Tanrıkulu H, Okay T, Doğusoy I. Esophageal foreign bodies in children and adults: 20 years experience. Ulus Travma Acil Cerrahi Derg 2013;19(3):229-34. https://doi. org/10.5505/tjtes.2013.22687.

16. Zhang S, Cui Y, Gong X, Gu F, Chen M, Zhong B. Endoscopic Management of Foreign Bodies in the Upper Gastrointestinal Tract in South China: A Retrospective Study of 561 Cases. Dig Dis Sci 2010;55(5):1305-12. https://doi.org/10.1007/s10620009-0900-7.

17. Goh BK, Chow PK, Quah HM, Ong HS, Eu KW, Ooi LL, et al. Perforation of the gastrointestinal tract secondary to ingestion of foreign bodies. World J Surg 2006;30(3):372-7. https://doi. org/10.1007/s00268-005-0490-2. 
18. Ashraf 0. Foreign body in the esophagus: a review. Sao Paulo Med J 2006;124(6):346-9. https://doi.org/10.1590/s151631802006000600010 .

19. Akkuzu MZ, Sezgin O, Yaraș S, Özdoğan O, Üçbilek E, Ateş F, et al. Foreign Bodies on the Path of Nutrition: Retrospective Evaluation of Our Clinical Experience. Med Bull Haseki. 2020;58:15-20. https://doi.org/10.4274/haseki. galenos.2019.5263.

20. J Völker, C Völker, P Schendzielorz, Schraven SP, Radeloff A, Mlynski R, et al. Pathophysiology of esophageal impairment due to button battery ingestion. Int J Pediatr Otorhinolaryngol. 2017;100:77-85. https://doi.org/10.1016/j.ijporl.2017.06.030.

21. Apilioğulları B, Ceran S.Foreign Bodies in the Esophagus: 117 Cases. Kocaeli Med J. 2021;10(1): 106-111.

22. Kim JK, Kim SS, Kim JI, Kim SW, Yang YS, Choet SH, et al. Management of foreign bodies in the gastrointestinal tract: an analysis of 104 cases in children. Endoscopy 1999;31:302304. https://doi.org/10.1055/s-1999-13.
23. Katsinelos P, Kountouras J, Paroutoglou G, Zavos C, Mimidis K, Chatzimavroudis G. Endoscopic techniques and management of foreign body ingestion and food bolus impaction in the upper gastrointestinal tract: a retrospective analysis of 139 cases. J Clin Gastroenterol 2006;40(9):784-9. https://doi. org/10.1097/01.mcg.0000225602.25858.2c.

24. Craig RM, Vanagunas AD. Foreign bodies in the eosophagus. In: Shields TW, editor. General thoracic surgery. Philadelphia: Lippincott Williams \& Wilkins 2000. p. 1763-7.

25. Ko HH, Enns R. Review of foodbolus management. Can J Gastroenterol 2008;22(10):805-8. https://doi. org/10.1155/2008/682082.

26. Higo R, Matsumoto $\mathrm{Y}$, Ichimura K, Kaga K. Foreign bodies in the aerodigestive tract in pediatric patients. Auris Nasus Larynx 2003;30(4):397-401. https://doi.org/10.1016/s03858146(03)00087-7.

27. Loh KS, Tan LK, Smith JD, Yeoh KH, Dong F. Complications of foreign bodies in the esophagus. Otolaryngol Head Neck Surg 2000;123(5):613-6. https://doi.org/10.1067/ mhn.2000.110616. 